\title{
The incubator hospital from the viewpoint of ergonomic
}

\author{
Sthephany Martins de A. Souza ${ }^{a}$; Vânia Maria Batalha Cardoso ${ }^{b}$. \\ ${ }^{a}$ Federal University of Amazonas \\ ${ }^{\mathrm{b}}$ Federal University of Amazonas and Head of the Ergodesign Service of University Hospital Getúlio \\ Vargas
}

\section{Introduction}

The incubator for newborns is a system specially designed to provide babies environmental qualities of the ideal closest to the womb, as they have difficulties to adapt to the external environment. Controls temperature, humidity and oxygen inside.

The infant assumes a dominant posture of flexion of the limbs and thus bending of the spine. According to Barradas [1], premature babies do not get the necessary neurological maturity, not enough time to stay in the intrauterine environment to develop this bending, resulting in muscle and other problems.

This work consists of an ergonomic analysis of the problems of neonatal incubator based on the method proposed by Moraes and Mont'Alvão [3] for the proposition regarding improvements to accommodate the newborn and correct posture, improve the quality of life of the newly born, to minimize future problems and reducing the time of hospitalization.

\section{Materials and Methods}

The methodology used for this intervention Ergonomizadora, in proposing improvements to neonatal incubator, and was proposed by Moraes Mont'Alvão [3]

We addressed the following steps of the intervention Ergonomizadora:

Ergonomic Assessment - Exploratory mapping of ergonomic problems, characterization and location of the Serial System .

Diagnose ergonomic - deepening and prioritization of problems and test predictions.

\section{Ergonomic Intervention}

\subsection{Neonatal Incubator System}

The Neonatal Incubator is an electro-medical equipment whose purpose is to keep the lives of newborn babies. It gives the newborn a thermo neutral environment - by controlling the temperature and relative humidity at acceptable levels, where the newborn maintains its normal body temperature at low metabolic rates, thus producing as little heat as possible.

The incubator gets systems and subsystems. Air circulation systems, heating systems, humidification systems, electronic systems. It took the full knowledge of the system, both the input and output, which is studying the requirements, what is needed to make the system work.

\subsection{Problems of System Man-machine task}

The questioning of the system seeks to achieve the maximum of information to, identify them and examine them. The solution of the problem depends largely on our analysis, according to the development of critical evaluation is possible and finally gets the right solutions.

Moraes and Mont'Alvão [3] categorize twentytwo ergonomic problems of the system manmachine task, among them we may classify the problems of the incubator and its relationship with the newborn:

\subsubsection{Ational}

In all procedures, intubation of the newborn, open to the side opening and the expert must do the procedure with the child more in the incubator as possible to avoid heat loss, avoiding death. Shares registered in the intubation procedure check the 
biomechanical constraints in the attack ational (Figure 1) because the top of the incubator prevents the movement of the instruments used by the physician.

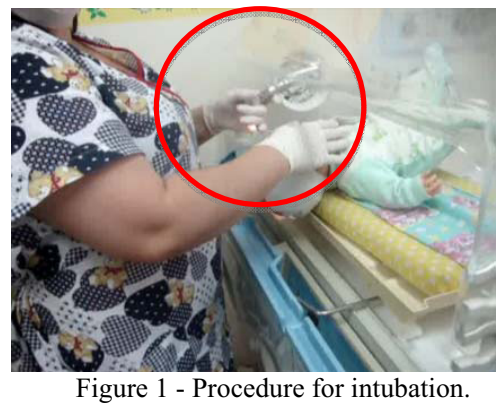

\subsubsection{Cognitive}

Since the incubator is a new environment for the newborn, there is a difficulty in decoding the environment. Meyerhoff [2] says that an infant is able to focus on objects at a distance of 20 to 30 centimeters apart and light and dark, so they sense the environment and also have their preferences.

The damp and dark environment of the uterus is different from the environment of the incubator is a passage and a sudden sharp turn. The IN does not solve the problem of a structural adjustment and so difficult to decode the IN environment.

\subsubsection{Movements}

According to Sweeney [4] states that the baby in the incubator has a neck hyperextension, which blocks development of the contraction of this region and their mobility. This position undermines the body movement of the newborn, and especially of its members. Impaired sensory and motor systems, because the position and angle of the bed provides a hyperextension of the neck.

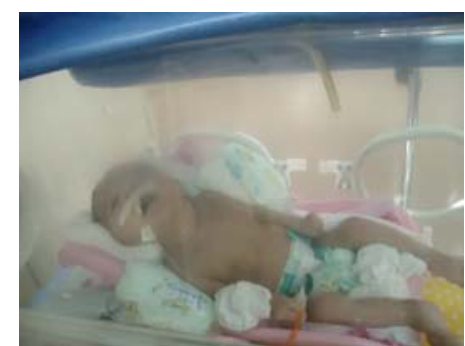

Figure 2 - Baby on the state of IN in neck hyperextension.

\subsubsection{Space}

The procedure for opening the lid of the incubator side there are two levers that close the incubator, which should be opened simultaneously, that gap gets noises that affect the newborn. (Figure 2)

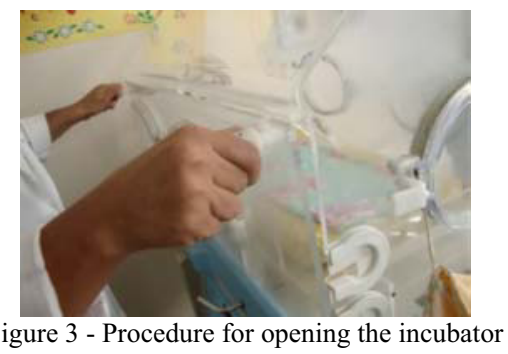

To release the cover operator must be careful not to make noise in the friction between the lid and the bottom of IN (Figure 4).

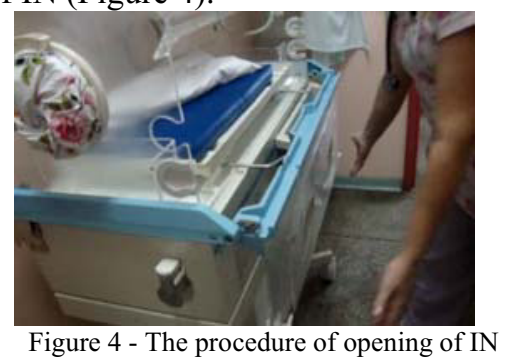

In elevating the head (Figure 5), the activation propagates noise can scare or harm the hearing of newborns. The IN has soundproofing problem because the dome is an external sound box that propagates inward, damaging the infants who need maximum silence in their treatment.

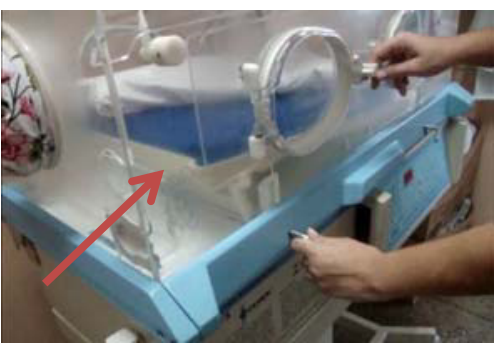

Figure 5 - Elevation of the bed IN

The incubator does not have a system that prevents direct light to the newborn. Operators provide a cloth for the comfort of the child (Figure $6)$.

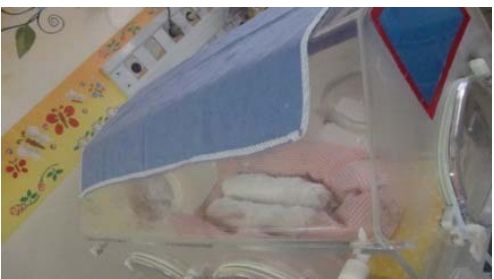

Figure 6 - IN covered with cloth to prevent direct illumination of the newborn.

In the opening mechanism of the incubator for dampers and insulating, but cannot prevent noise. The closing is done manually, which may cause an accident. (Figure 7). 


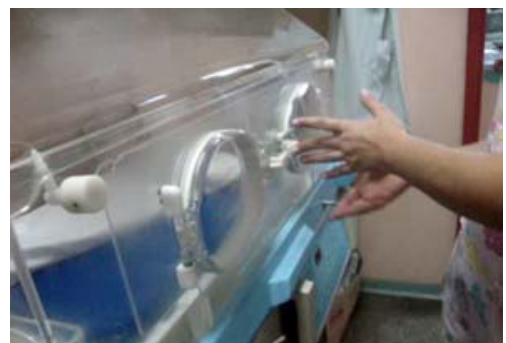

Figure 7- Closing the open side of the dome.

\subsubsection{Physical and environmental}

The newborn has less fat than an older child, apart from small amount of power in stock.

Has a condition forced to adapt, so he is in stress, fatigue, exhaustion, using a high amount of energy, losing a lot of temperature. When you open the incubator to treat the newborn or change the position of temperature sensor, the temperature drops.

Another problem is related within the incubator attached to the acoustic system. A closed box with a body is vulnerable in the propagation of sound inside the box, so does the RN.

Another feature that interferes with the comfort of newborns is the continuous illumination of fluorescent lights on the baby, because their physiological and biochemical effects that this type of lighting involves. The bright light can affect the normal development of the retina, can possibly cause blindness, Menom, [3]. The best solution to the $\mathrm{RN}$ has a dream home, it is with low light intensity of the NICU. Sleep and rest are considered important for recovery of the baby, therefore there must be a greater comfort for the treatment to be achieved in full.

All doctors surveyed approve of structural change in the IN, because the child suffers from changes in the uterus for the extra uterine. We also welcome the intervention of ergonomic IN.

Studies on the behavior of the newborn baby is being made in order to identify patterns that reflect maturation or features of their adaptive responses perceptual, cognitive or sensory-motor skills.

From the issues addressed in the theoretical framework and the problems identified in study execution, characterized that must meet the requirements and design parameters that guide it.

\section{Conclusions}

In this study, we studied the needs of the newborn using a neonatal incubator (IN), due to lack of maturity of neonates. In the incubator, the newborn (NB) may experience difficulties in adjusting posture due to a difference in structure between the incubator and the intrauterine environment.
Table 1 - Requirements and Parameters

\begin{tabular}{|c|c|c|}
\hline \multicolumn{2}{|r|}{ Requirements } & Parameters \\
\hline 1 & $\begin{array}{l}\text { Accommodations that } \\
\text { allow the internal positions } \\
\text { in the womb. }\end{array}$ & $\begin{array}{l}\text { Using concepts of Kangaroo Care, } \\
\text { hammocks and shape of the womb. }\end{array}$ \\
\hline 2 & decrease Noise & Use of acoustic shock and technical \\
\hline 3 & \begin{tabular}{l}
\multicolumn{2}{c}{ Minimize } & friction \\
between the incubator \\
babies, and professional \\
instruments.
\end{tabular} & $\begin{array}{l}\text { Structure of the incubator } \\
\text { movement in conformation with the } \\
\text { tools and professional baby }\end{array}$ \\
\hline 4 & $\begin{array}{l}\text { Decrease the heat loss, } \\
\text { temperature of the newborn } \\
\text { in clinical procedures. }\end{array}$ & $\begin{array}{l}\text { Subsystems to facilitate procedures } \\
\text { without compromising the internal } \\
\text { temperature of the incubator }\end{array}$ \\
\hline 5 & $\begin{array}{l}\text { Facilitate intubation } \\
\text { without compromising the } \\
\text { temperature and comfort of } \\
\text { the baby. }\end{array}$ & $\begin{array}{l}\text { Subsystem internal support and } \\
\text { protection of the baby. }\end{array}$ \\
\hline 6 & $\begin{array}{l}\text { Doors lock with safer } \\
\text { and quieter. }\end{array}$ & $\begin{array}{l}\text { Doors and lock system with resilient } \\
\text { material and which does not generate } \\
\text { noise. }\end{array}$ \\
\hline 7 & $\begin{array}{l}\text { Reduce the handling of } \\
\text { the newborn }\end{array}$ & $\begin{array}{l}\text { Subsystem that allows rotation of } \\
\text { the baby without handling. }\end{array}$ \\
\hline
\end{tabular}

With the ergonomics and the concepts we analyze the conditions within its comfort when using the RN Neonatal Incubator. We tried to raise the large amount of information in order to achieve the requirements and parameters are essential for the continuity of the project.

To provide better health and quality of life for the newborn, taking into account all issues raised in this research, the project will continue developing in order to bring the proposals and solutions to the problems encountered.

That said, it is believed that a new structure of the incubator in the neonate allows comfortable accommodation and quality of life by facilitating the maturation and development engine, providing a proper posture, designing better quality of life for newborns and decreasing length of hospital.

\section{References}

[1] Barradas, J. The relationship between premature placement in Kangaroo Mother Care and early neuro-psychomotor development. Pediatric Journal (RJ), 2006.

[2] Meyerhoff, Michael. Cognitive and social development of a newborn. Publisher D. (2006). Available at $<$ www.itaipulandia.pr.gov.br> Visited on: 25/05/2011.

[3] Moraes, Anamaria; Mont'Alvão, Claudia. Ergonomics, Concepts and Applications. 2nd Edition, Rio de Janeiro: 2AB; Workshop Series, 2010

[4] Sweeney, JK, Swanson, MW Newborns and babies at risk: management and monitoring in the NICU. Publisher, Umphered DA. Neurological Physiotherapy. 2nd ed. São Paulo, 1994. p. 181-236. 